\title{
Right Ventricular Function in Juvenile Idiopathic Arthritis Patients
}

\author{
Martin Koestenberger • William Ravekes
}

Received: 17 July 2012/ Accepted: 19 July 2012/Published online: 8 August 2012

(C) Springer Science+Business Media, LLC 2012

To the Editor,

We read with interest the article by Abul et al. [1] entitled The Forgotten Chamber: Right Ventricular Functions in Juvenile Idiopathic Arthritis. In our opinion, this is an excellent statement describing the current need for a more detailed investigation of the right ventricle (RV). The authors clearly state that a need exists for a detailed evaluation of the right ventricular function parameters (e.g., the tricuspid annular peak systolic velocity (TAPSV) in the pediatric population with juvenile idiopathic arthritis) [1].

For the convenience of the pediatric cardiology audience, especially centers performing detailed echocardiographic investigations, we add that quite recently, our group has published normal TAPSV values with $z$-scores for healthy pediatric patients [2]. In addition, we also have described decreased TAPSV values for pediatric patients with congenital heart diseases [3].

We thank the authors for addressing the need for careful and systematic evaluation of the RV in the pediatric population, especially patients with juvenile idiopathic arthritis. In our opinion, the RV function should be investigated carefully both in patients with congenital heart disease and in those with diseases that might influence the RV function. We hope that with increasingly available normal reference values and $z$-scores for this population, quantification of RV function will become an easy available tool for all sonographers.

\section{References}

1. Abul MH, Erguven M, Ozben B, Ayhan YI (2012) The forgotten chamber: right ventricular functions in juvenile idiopathic arthritis. Pediatr Cardiol 33:739-743

2. Koestenberger M, Nagel B, Ravekes W, Avian A, Heinzl B, Cvirn G, Fritsch P, Fandl A, Rehak T, Gamillscheg A (2012) Reference values of tricuspid annular peak systolic velocity in healthy pediatric patients, calculation of $z$-score, and comparison to tricuspid annular plane systolic excursion. Am J Cardiol 109:116-121

3. Koestenberger M, Nagel B, Ravekes W, Avian A, Heinzl B, Fandl A, Rehak T, Sorantin E, Cvirn G, Gamillscheg A (2012) Tricuspid annular peak systolic velocity $\left(S^{\prime}\right)$ in children and young adults with pulmonary artery hypertension secondary to congenital heart diseases, and in those with repaired tetralogy of Fallot: echocardiography and MRI Data. J Am Soc Echocardiogr. doi: 10.1016/j.echo.2012.06.004

\section{Koestenberger $(\bowtie)$}

Division of Pediatric Cardiology, Department of Pediatrics, Medical University Graz, Auenbruggerplatz 30, 8036 Graz, Austria

e-mail: koestenbergerm@gmx.at;

Martin.Koestenberger@medunigraz.at

W. Ravekes

Division of Pediatric Cardiology, Johns Hopkins University

School of Medicine, Baltimore, MD, USA 